\title{
Study of the dynamics of estuarine and coastal waters using remote sensing: the Tinto-Odiel estuary, SW Spain
}

\author{
Ojeda, J. ${ }^{1}$, Sanchez, E. ${ }^{1 *}$, Fernandez-Palacios, A. $^{2}$ \& Moreira, J. M. ${ }^{2}$ \\ ${ }^{1}$ Department of Physical Geography, University of Sevilla, C/ María de Padilla, s/n, 41004 Sevilla, Spain; \\ ${ }^{2}$ Servicio de Evaluación de Recursos Naturales,Consejería de Medio Ambiente, Junta de Andalucía, \\ Pabellón de Nueva Zelanda, Avenida de las Acacias s/n, Isla de la Cartuja, 41092 Sevilla, Spain; \\ * Tel. +34 5 4551366; Fax +34 5 4551351; E-mail zujar@obelix.cica.es
}

\begin{abstract}
This paper deals with the application of satellite images to characterize some aspects of the circulation dynamics of the Tinto-Odiel estuary using turbidity pattems as 'natural tracers'. 15 images (Landsat TM and Spot HRV) were processed to provide synoptic, instantaneous views of the circulation pattems under different environmental conditions. In addition, a comparison was made between results of oceanographic field work, using biplanes and fluorescent tracers, and satellite image turbidity pattems used as 'ground truth' data for specific hydroclimatic situations. This approach allowed (1) the identification and mapping of dynamic processes of interest during a theoretical tidal cycle, (2) the elaboration of additional information on the 'flow schemes' at the mouth of the estuary with improved spatial and temporal resolution, and (3) the supply of basic data to improve the knowledge of exchange processes between estuarine and coastal waters. The results of this study are considered to be useful for the management of the estuarine system.
\end{abstract}

Keywords: Estuarine dynamics; Flow scheme; Satellite image; Turbidity pattem; Water exchange.

\section{Introduction}

The Tinto-Odiel estuary is forrned by the confluence of the rivers Tinto and Odiel on the Atlantic coast of SW Spain near Huelva (Fig. 1). The tidal type in this stretch of coast is mesotidal (average tidal range $2.10 \mathrm{~m}$ ) and semidiurnal (Borrego 1992), with a slight daily irregularity as shown by the data taken at the harbour of Huelva (Borrego \& Pendón 1989). Average values for the speed of the tidal currents in the main channel of the estuary are shown in Table 1.

The presence of marshes, dunes and beaches associated with the estuarine dynamics mates this area very valuable from an ecological point of view, and this is the reason why many of these areas have been declared Natural Protected Areas by the regional government. On the other hand, as in most European estuaries, many activities and fonns of intensive land use are found on its banks: harbours (Huelva and Punta Umbría), cities (Huelva), tourist resorts (Punta Umbría, Mazagón), petrochemical industrial settlements and intensive agricultural areas. These activities influence the dynamics of the estuary (Ojeda 1992) and threaten the quality of the water. This situation led the Regional and National Administration to promote studies focused on the physical characteristics and dynamics of the estuary (Gil 1987), and to assess the capability of dispersion and renewal of estuarine water (Anon. 1982). In these studies the behaviour of tidal currents and their interaction with coastal currents at the mouth of the estuary are thought to be determining factors, as long as the fresh water inflow from rivers is small and very irregular (as is usual in a Mediterranean climate).

As part of its working prograrnme, the AMA, Agencia de Medio Ambiente (Regional Environmental Agency) of the Junta de Andalucía (the provincial Board) has started the 'Monitoring Prograrnme of the Quality and Dynamics of the Marine Waters and the Coastal Zone in Andalusia Using Remote Sensing Techniques'. One of the aims of this prograrnme is the evaluation of remote sensing techniques as a complementary source of information in the study of coastal water dynamics. In this programme, satellite images provide an additional basis for the location of representative sarnpling points for the evaluation water quality; they are algo used for the interpretation of periodical water samples taken in the area by the authorities in charge of the water quality (Plan de Policía de Aguas del Litoral de Andalucía). Satellite images are regarded essential sources of information for the Environmental Infonnation System of Andalusia (Sistema de Información Ambiental de Andalucía, SinarnbA). This papel provides the first results of an investigation upon this basis. 


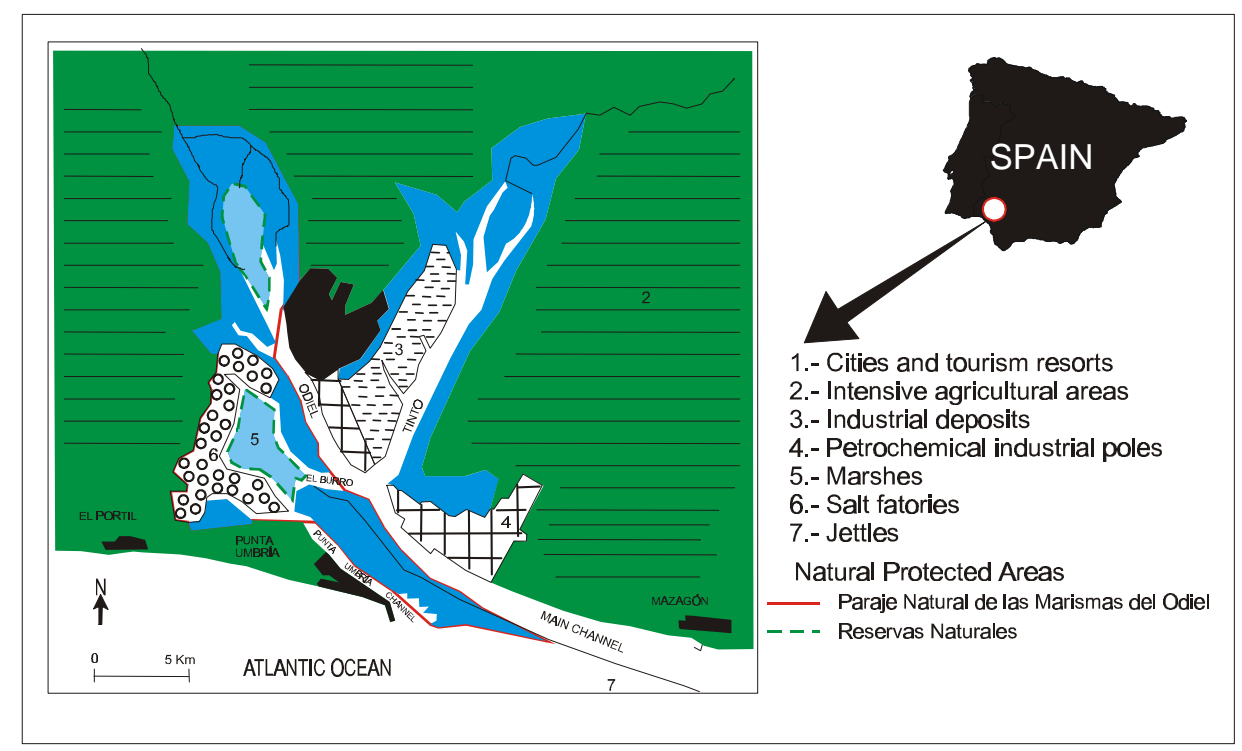

Fig. 1. Map of the study area.

\section{Objectives}

The main objective of this paper focuses on the use of satellite images to characterize some aspects of the water dynamics of the Tinto-Odiel estuary. Turbidity is used as a 'natural tracer' because it clearly shows the water circulation pattems involved (Balopoulos et al. 1986). The qualitative interpretation of these turbidity pattems allows lo:

(1) characterize the main aspects ofthe estuary dynamics (tidal currents, turbidity maximum, coastal and estuarine water mixing processes, etc.).

(2) assess their contribution in the definition of 'flow schemes' in the estuary mouth.

Table 1. Average speed (m/sec) of the tidal current in the main channel (Anon. 1988).

\begin{tabular}{cc}
\hline Spring tide (flood) & 0.49 \\
Spring tide (ebb) & 0.56 \\
Neap tide (flood) & 0.27 \\
Neap tide (ebb) & 0.29 \\
\hline
\end{tabular}

The results of the satellite image interpretation were compared with the results obtained in field studies undertaken for the same purpose by CEDEX (Centro de Experimentación de Obras Públicas) in 1982. Satellite images contribute with a better spatial and temporal resolution and they also provide maps for testing the results obtained in the field studies and from models derived from these studies.

\section{Methods}

The initial information was provided by 15 satellite images (Landsat TM and Spot HRV) covering the Tinto-Odiel estuary. These images were selected from the Image Library of the AMA in an attempt to choose as many different hydrodynamic situations as possible.

Image processing was very simple. Firstly, a mask was applied to each image by choosing a threshold (specific for each image) in one of the near-infrared bands (usually, TM 5 or HRV 3 ) in arder to separate land from water. Then, the values corresponding to the estuarine and coastal waters in a visible channel were density-sliced ${ }^{1}$ and colour-coded ${ }^{1}$. The intervals used in the density slicing are different for each image, since the atmospheric contribution to the water radiance varies and the minimum value is

\footnotetext{
${ }^{1}$ Density slicing is an enhancement procedure whereby fue digital numbers of an image are divided into a series of analyst specified intervals. All of the digital numbers falling within each interval in the input image are then displayed as a single digital number in the output image. At this occassion, each level is shown in a different colour.
} 
different for each image. Although turbidity is revealed fairly well in all the visible channels, i.e. the TM bands 1,2 and 3, and the HRV bands 1 and 2 (Chesire et al. 1985), we needed to avoid the bathymetric effect and the atmospheric dispersion effect. Therefore we left out the shorter wavelengths, especially TM band 1.

Finally, 12 images were selected. They are presented in Fig. 2a-n. These colour pictures show turbidity patterns which can easily be interpreted qualitatively from a dynamic perspective (horizontal movement of the surface waters) without the need for geometric and radiometric corrections that are required for quantitative studies. The colours blue, green, yellow, orange and red, in this order, show increasing turbidity levels. Therefore, our approach concentrates on visual interpretation.

Because of the variety of dynamic situations shown in the 12 selected images and the cyclic character of some of the main factors that control the turbidity patterns (tide, for example), we are able to characterize the most typical situations in the dynamic behaviour of the estuary. On the other hand, the comparison of turbidity patterns extracted from the images with the results of the field work (Anon. 1982) may also result in some conclusions about the water circulation in the estuary - using the satellite images as ground truth data for specific hydrodynamic and meteorological conditions.

\section{Results}

\section{Water dynamics in the Tinto-Odiel estuary}

The 12 selected images correspond to 12 synoptic turbidity patterns, associated with different hydrodynamic conditions in the estuary (tidal phase and coefficient, wind, etc). As a first result of the image interpretation, turbidity patterns can be used as 'natural tracers' in order to draw certain conclusions about the behaviour of this estuary over a tidal cycle:

\section{Tidal flood current}

The tidal flood currents are established in the main channel of the estuary with a certain time lag in relation to the theoretical tidal phase change. This time lag can even be longer than $2 \mathrm{hr}$, depending on the tidal coefficient (the greater the coefficient, the longer the time lag), and it is related to the inertia of the still ebbing waters in the estuary (Fig. 2k).

However, this time lag has different characteristics on either side of the main channel. At the lefthand side (facing downstream) the time lag is shorter and the flood tidal currents are established sooner than at the right-hand side, next to the jetty (7 in Fig. 1) which was built to protect the entrance to the harbour (Coriolis force, greater depth and inertia). Then, there is a 1 to 2-hr period after the tidal phase change in the coastal waters during which a 'two-way circulation' occurs in the mouth of the estuary (Fig. 2j). This situation may have changed by the construction of the harbour of Mazagón (Fig. 2m).

Once the tidal flood currents are established in the whole section of the main channel (Fig. 2b), the tidal wave passes through it homogeneously ( 2 to $6 \mathrm{hr}$ during the flood phase), while the highest level of turbidity occurs upstream.

\begin{tabular}{|c|c|c|c|c|}
\hline \multicolumn{5}{|c|}{ Fig. 2. Water dynamics in the Tinto-Odiel estuary } \\
\hline & Date & $\begin{array}{l}\text { Pressure-corrected } \\
\text { water height }(\mathrm{m})\end{array}$ & Coefficient & $\begin{array}{c}\text { Time to }(-) \text { and from }(+) \\
\text { low tide }\end{array}$ \\
\hline a. & $17 / 11 / 91$ & 2.61 & 0.66 & $-6 \mathrm{~h} 20$ \\
\hline b. & 09/05/91 & 2.59 & 0.65 & $-6 h 06$ \\
\hline c. & $07 / 02 / 87$ & 2.13 & 0.34 & $-5 h 22$ \\
\hline d. & $26 / 08 / 90$ & 1.08 & 0.45 & $-1 \mathrm{~h} 00$ \\
\hline e. & $15 / 02 / 90$ & 0.97 & 0.51 & -0h 54 \\
\hline f. & $13 / 08 / 91$ & 0.41 & 0.83 & +0h 19 \\
\hline g. & $18 / 04 / 87$ & 0.72 & 0.57 & $+0 h 43$ \\
\hline h. & 09/07/90 & 1.13 & 0.78 & $+1 \mathrm{~h} 39$ \\
\hline j. & $01 / 01 / 91$ & 0.89 & 0.97 & $+1 \mathrm{~h} 54$ \\
\hline k. & $15 / 10 / 85$ & 0.77 & 1.05 & $+1 \mathrm{~h} 56$ \\
\hline $\mathrm{m}$. & $14 / 07 / 92$ & 1.59 & 0.76 & $+2 \mathrm{~h} 33$ \\
\hline n. & $15 / 06 / 93$ & 2.57 & 0.57 & $+5 h 56$ \\
\hline
\end{tabular}




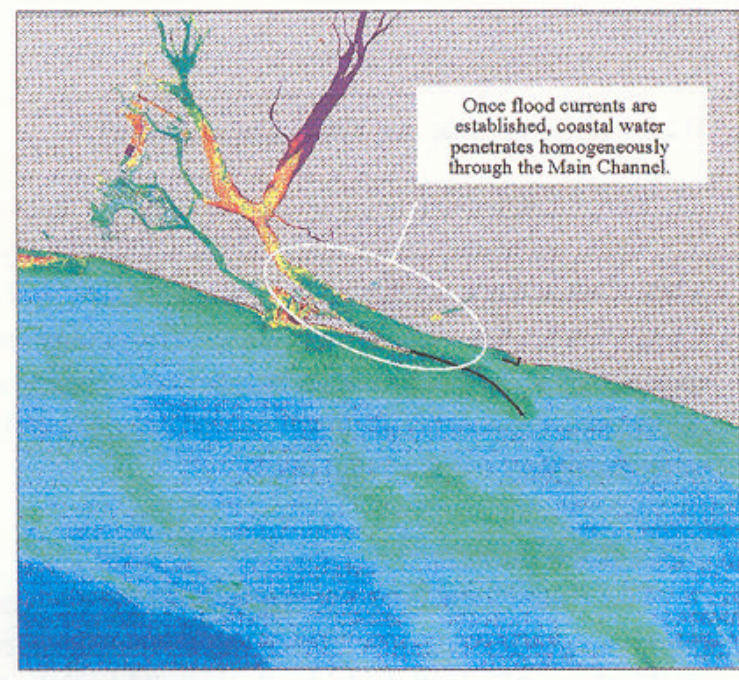

a

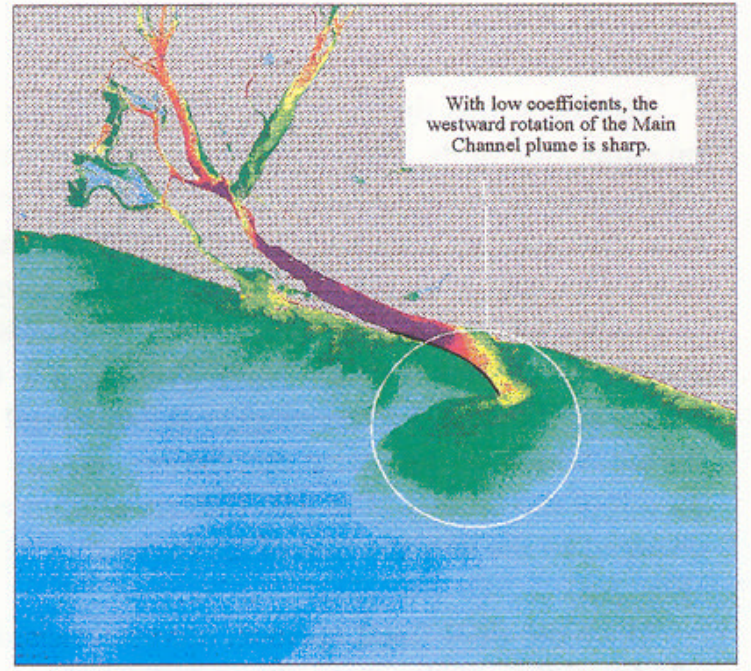

c

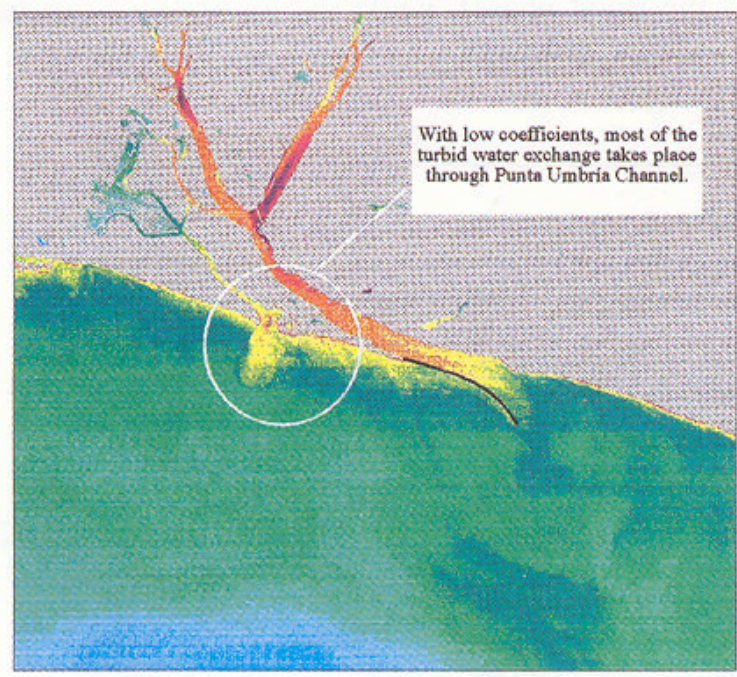

e

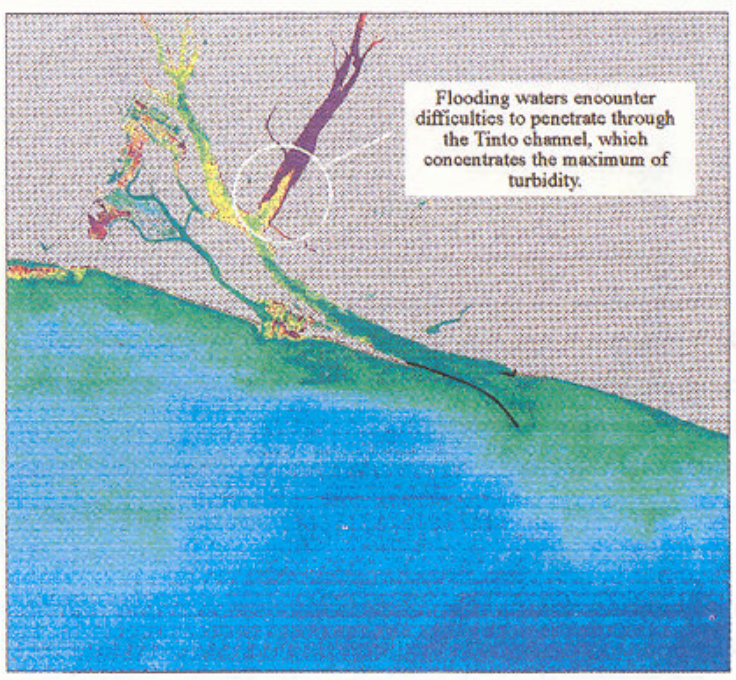

b

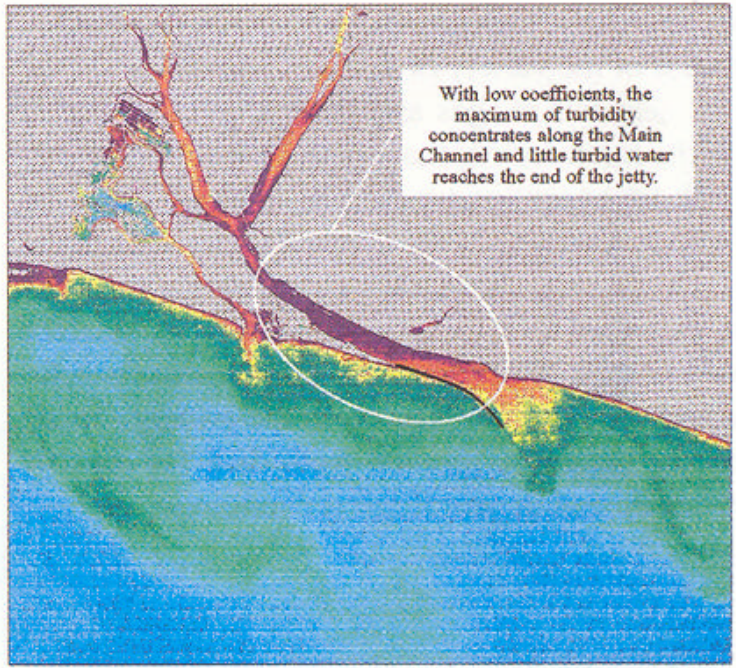

d

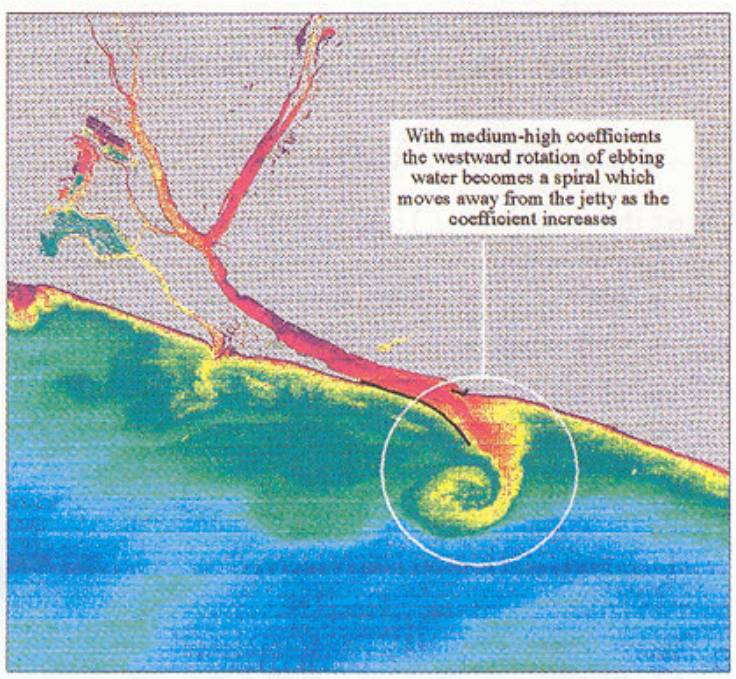

f

Fig. 2a-f 


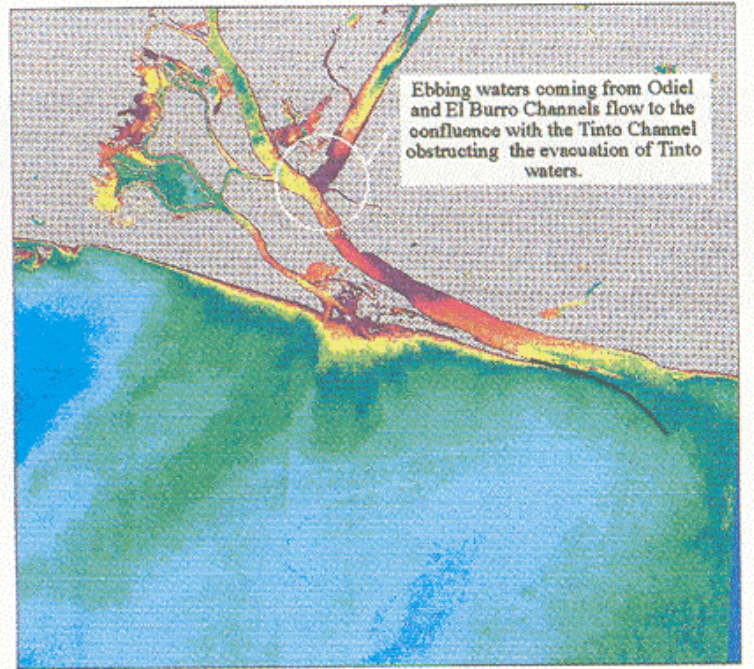

g

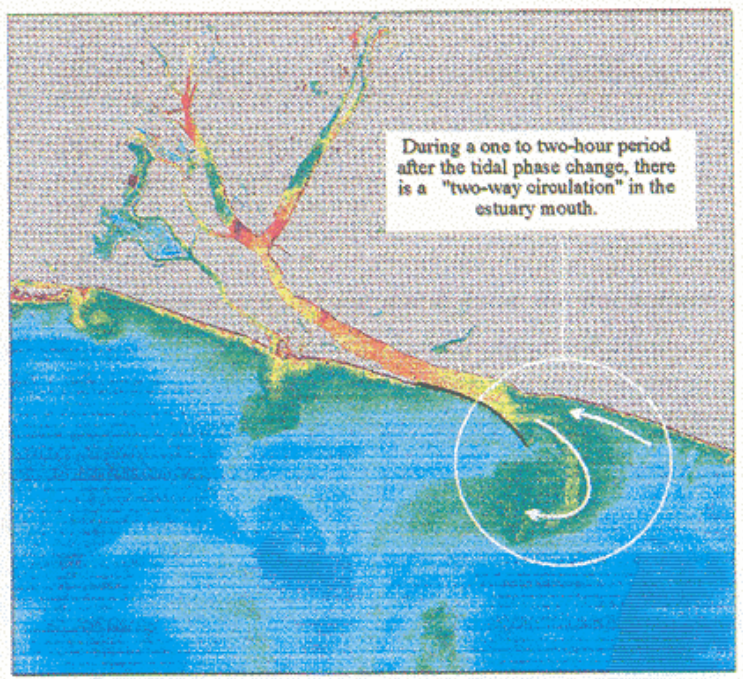

j

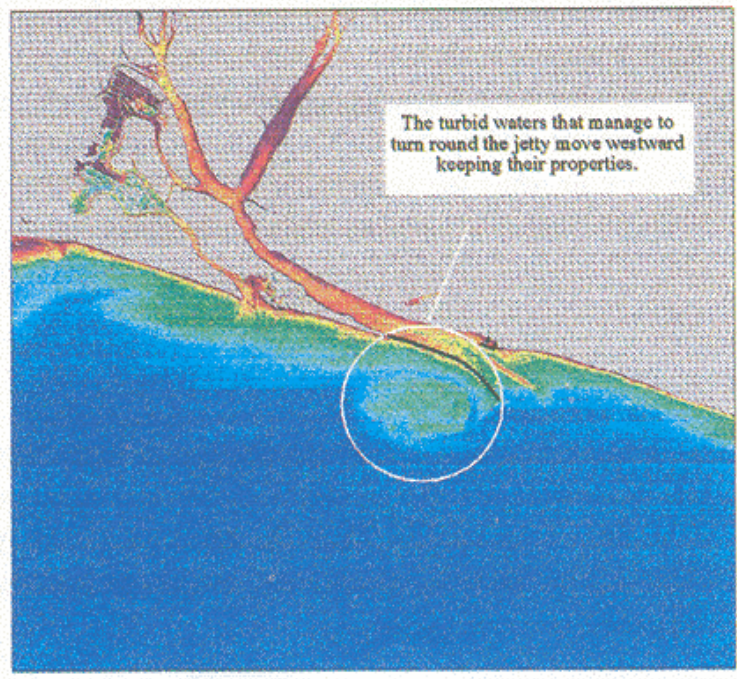

m

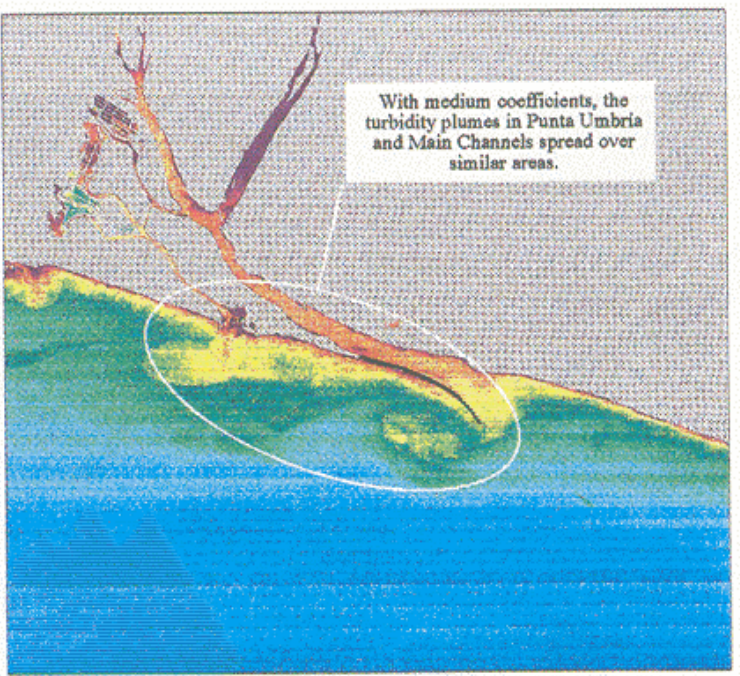

h

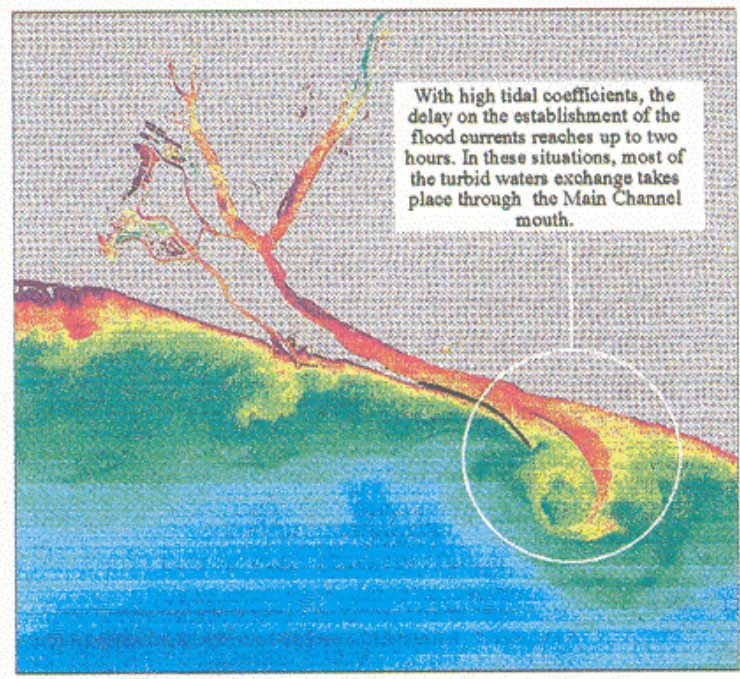

k

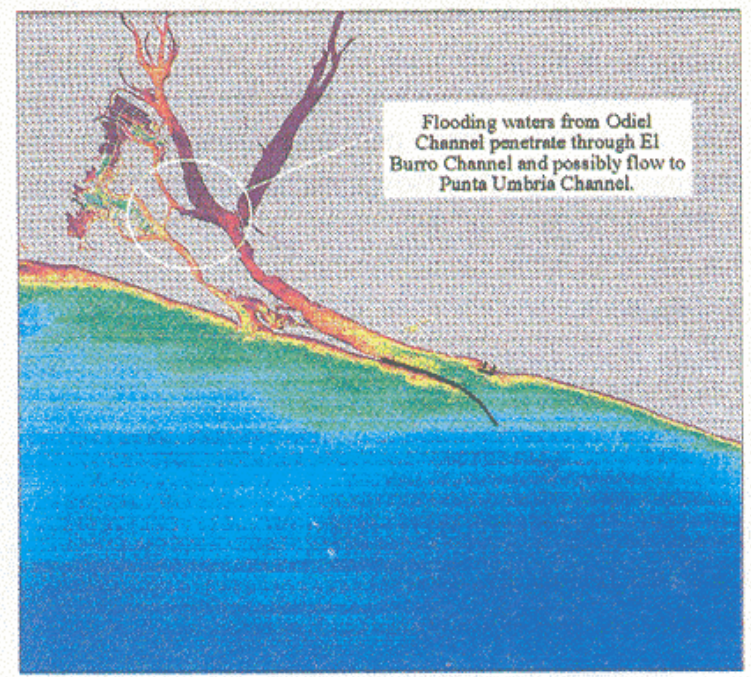

n

Fig. 2g-n 


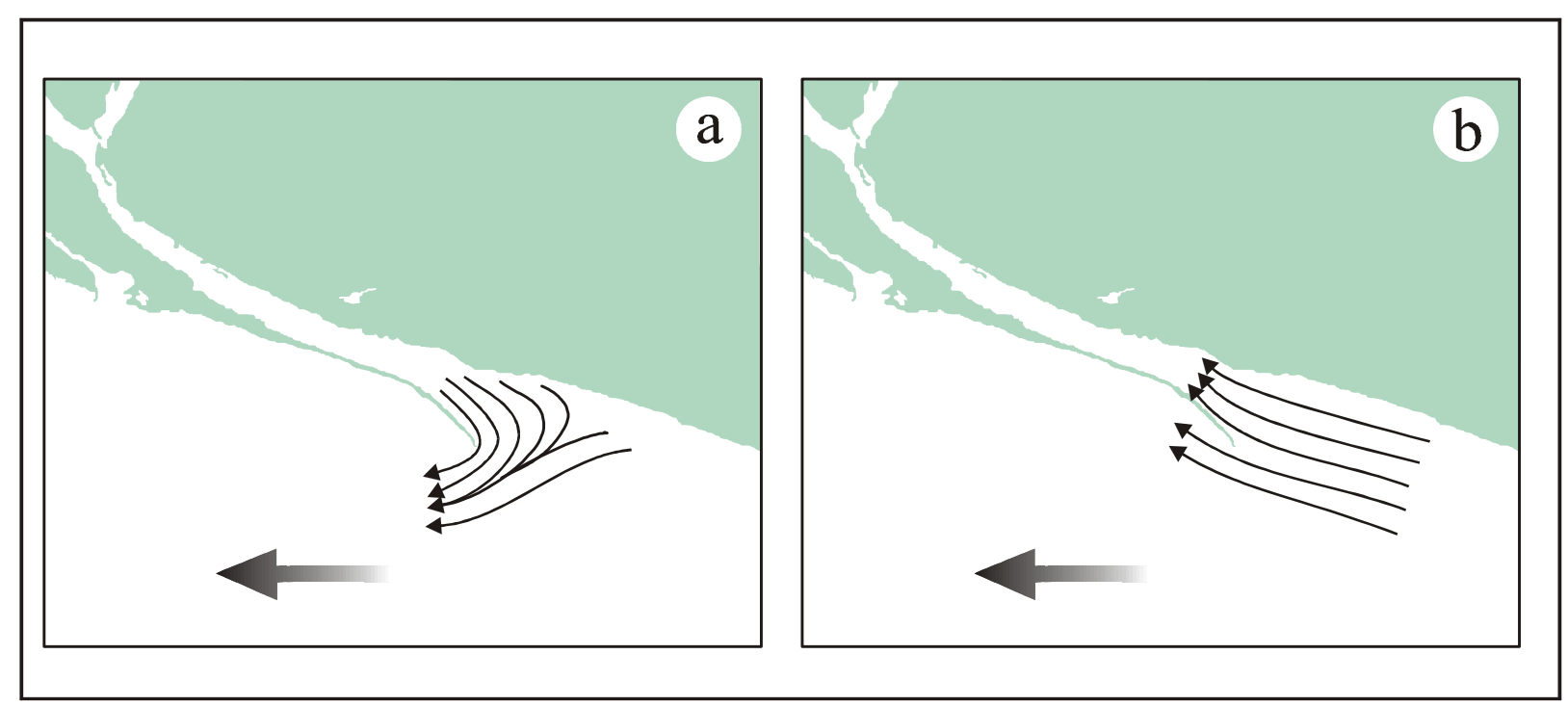

Fig. 3. Flow scheme in the mouth of the estuary with a westward coastal current: (a) ebb tidal currents; (b) flood tidal currents. (Anon. 1982).

\section{Flood wave propagation}

The homogeneous movement of the flood wave in the main channel contrasts with its different behaviour after the confluence of the two rivers:

- the tidal wave moves more easily through the Odiel channel, due to its wider section and its advantageous geometric orientation in relation to the main channel (Figs. $2 \mathrm{a}$ and $2 \mathrm{~b}$ );

- the tidal wave is delayed and meets more difficulties to penetrate into the Tinto channel due to its smaller section and its disadvantageous geometric orientation (almost $90^{\circ}$ ) in relation to the main channel (Figs. $2 \mathrm{a}$ and $2 b)$;

- part of the water that is moved upstream in the Odiel channel by the flood current penetrates through the El Burro channel and possibly flows into the Punta Umbría channel (Figs. 2a, 2b and 2n).

\section{Ebb tide phase}

The tidal flood currents continue during some time after the high tide has established theoretically. In this sense, the time lag during the establishment of the ebb currents is similar to the delay in the establishment of the flooding currents. The only difference is that for the ebb currents it is shorter, due to the estuary configuration (less inertia, gravity, boundary effects, etc.).

The Tinto channel seems to encounter difficulties in releasing its water during the ebb tide phase. The water from the Odiel and El Burro channels flows into the confluence with the Tinto, obstructing its ebbing water, as shown by the turbidity pattems in Fig. $2 \mathrm{~g}$.

During ebb tide interesting patterns of turbidity plumes can be found; these are generated by the estuarine ebbing waters once they have reached the coastal waters. In this sense, the tidal phase and coefficient seem to be the main controlling factors as demonstrated by the similarities between the turbidity patterns when both parameters have similar values (Figs. $2 \mathrm{~h}$ and $2 \mathrm{~m}$, Figs. $2 \mathrm{f}, 2 \mathrm{j}$ and $2 \mathrm{k}$ ).

A remarkable characteristic is the persistence of a 'westward rotation' of the ebbing waters, which is observed in almost all of the images referring to the ebb tide phase.

As shown in Figs. $2 \mathrm{j}$ and $2 \mathrm{k}$, the inertia of the water movement during the ebb tide phase extends this phase up to $2 \mathrm{hr}$ after the beginning of the flood phase in the coastal waters. As stated above, this time lag is directly related to the current intensity and the water volume in motion, that is, the tidal coefficient. 


\section{Turbidity maximum}

Finally, under certain hydrodynamical conditions, the turbidity pattems precisely define the location of the 'turbidity maximum' (Figs. $2 \mathrm{c}$ and $2 \mathrm{~g}$ ) whose position depends on the tidal coefficient and phase and the rivers discharge.

\section{Comparison with the 'flow schemes'}

As a result of the interpretation of the turbidity patterns observed on the images, it is possible to extract a more applied kind of information by comparing these patterns with the flow schemes resulting from field work with biplanes and fluorescent tracers. This comparison will improve our knowledge of estuarine dynamics and the dispersion and renewal processes of estuarine waters.

CEDEX carried out an intermittent series of field campaigns from October 20th to December 4th, 1981 with the aim to select the basic parameters in order to define a dispersive renewal model in the TintoOdiel estuary. One of the objectives was to establish 'flow schemes' in the mouth of the estuary. This field work was considered essential, since it is the determining factor in the process of water exchange between the estuary and the sea, and hence in the process of the transportation of soluble and suspended products by the estuarine waters into the sea. Thus, during the ebb phase, a certain volume of water is carried off, but only part of it is incorporated again in the next flooding flow, while the remainder joins the dominant coastal water flow (which usually runs parallel to the coastline). Therefore, the interaction between the tidal currents and the dominant coastal water flow determines this water exchange process.

Complex flow schemes result from this interaction, although many situations are repeated due to the cyclic character of many of the controlling factors. Hence it is possible to define characteristic flow schemes for most of the stable situations (a complete characterization would require toa many simultaneous obervation points, long-term field studies and would therefore be very costly and time consuming).

The basic information used to define this typical flow scheme came from the boat tracking of biplanes and fluorescent dyes used as tracers during the 10 days the CEDEX field work lasted. The results were represented as dynamic schemes that showed important variations during the tidal phase change periods, but remained more stable during the central moments of each tidal phase $(2-5 \mathrm{hr})$. The results can be summarized in four flood and ebb situations, depending on the coastal water eastward or westward dominant flow direction.

\section{The westward dominant coastal water flow}

\section{Flow of the flood currents}

In the littoral current configuration, flood currents are established first on the left-hand side of the estuary, as the area next to the jetty is deeper and the ebbing water mass inertia is greater on this side (Fig. 3). This scheme is similar to the one already interpreted from the satellite images (two-way flow). The ebb phase flow scheme is more interesting: the released waters turn westward, while the turning degree depends on the coastal water flow (the more intense the flow, the more the ebbing waters bend) and the tidal coefficient (the higher the coefficient, the less the waters curve). In this flow scheme, only the water that manages to tum round the jetty does not retum to the estuary during the following flooding tide.

A closer analysis ofthe satellite images would allow us to verify this scheme and, due to the synoptic character and multitemporal approach that the images provide, even to refine it and Tender it useful from an environmental point of view.

All the images at the ebb tidal phase seem to follow this scheme, with the ebbing waters tuming westward at the mouth of the estuary, although the local hydrodynamic conditions (i.e. wind, waves, etc), may be very different.

However, this westward water rotation takes different configurations basically as a function of the tidal coefficient. With low coefficients (Fig. 2c) the inflexion is sharp whilst with high coefficients (Figs. $2 \mathrm{~h}$ and $2 \mathrm{k}$ ) the inflexion turns into a spiral that moves away from the jetty as the coefficient increases. Regarding this aspect, the CEDEX results could clearly be improved. 
In certain situations (Figs. $2 \mathrm{~h}$ and $2 \mathrm{~m}$ ) the water released from the estuary passes beyond the end of the jetty and moves westward, keeping its physical properties. This is important for the renewal of the estuary water and it also confirms the westward displacement of the coastal water.

\section{Exchange in the Punta Umbría channel}

During the field work the coastal-estuarine water exchange in the Punta Umbría channel was not taken into account, but the satellite images reveal the importance of this process:

- with low tidal coefficients the exchange of turbid water (not the entire volume of water being exchanged) takes place through the Punta Umbría channel (Fig. 2c), since the turbid water in the majo channel hardly reaches the end of the jetty;

- with medium tidal coefficients (Fig. 2h), the turbidity plumes in both channels (Punta Umbría and the main channel) show a similar spatial development;

- with high tidal coefficients (Figs. $2 \mathrm{j}$ and $2 \mathrm{k}$ ) the exchange of turbid water takes place mainly through the main channel mouth.

Therefore, the Punta Umbría channel seems to play an important role in the exchange of coastal and estuarine water. Previous work (Borrego 1992) pointed to the interesting dynamic behaviour of this channel that seems to release part of the estuarine water coming from the Odiel channel through the El Burro channel. Borrego justified this connection by means of the differential behaviour of the two channels, which is due to:

(1) differences in tidal wave transportation - while in the Odiel channel the tidal range increases upstream, the tidal range in the Punta Umbría channel decreases upstream, that is, the Odiel channel is hypersynchronic, while the Punta Umbría channel is hyposynchronic;

(2) the 5 to 15-minute delay in the establishment of the tidal phases in the Punta Umbría channel.

Finally, the repetition of the turbidity patterns when the tidal coefficient and phase are similar, seems to give these parameters an essential role in the water exchange between the estuary and the coastal zone.

\section{The eastward dominant coastal water flow}

The flow schemes resulting from the field studies are shown in Fig. 4. Following this model, the flood currents are established sooner at the left hand margin, since this area is protected from the coastal dominant currents by the jetty. In this sense, there is a double flow situation, similar to the previous modelo When the homogeneous flooding flow is established, most of the water penetrates next to the jetty (right margin), but part of it is incorporated into the eastward coastal current, starting from a line that is further away from the mouth of the estuary as the tidal coefficient increases. On the other hand, the flow lines during ebb tide take a configuration parallel to the coastline.

Although the eastward dominant flow was expected to occur frequently in this afea, no image revealed this scheme, due to the effect of wind at a regional scale - the estuary is located in the Golfo de Cádiz, under the influence afea of westerly winds and Atlantic fronts. 


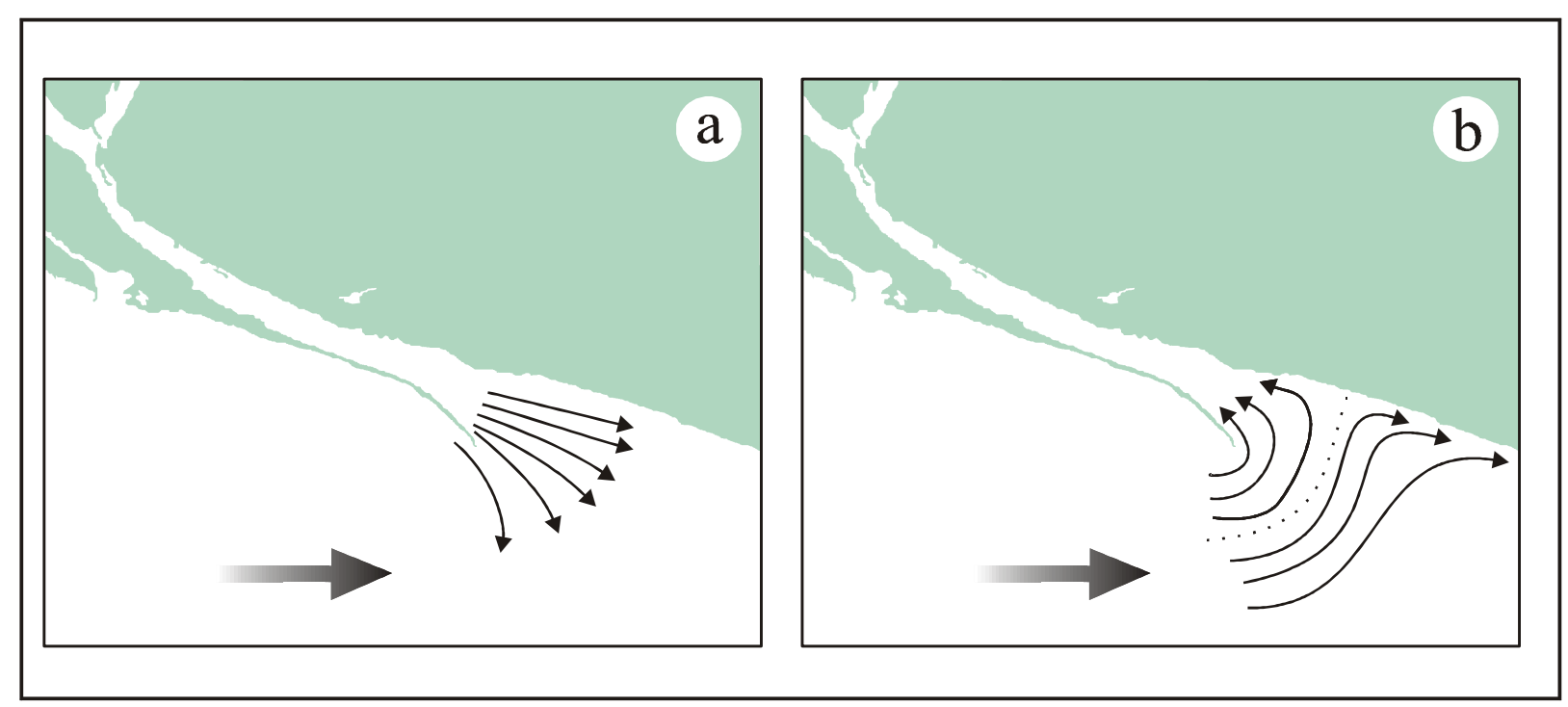

Fig. 4. Flow scheme in the mouth of the estuary with a eastward coastal current: (a) ebb tidal currents; (b) flood tidal currents. (Anon. 1982).

\section{Discussion}

After comparing the information obtained from the satellite images with the flow schemes derived during the field work, some points require discussion:

1. From an instrumental point of view, it seems obvious that the use of turbidity as a natural tracer in estuaries allows an effective characterization of some aspects of the estuarine dynamics. This is evident in ebbing situations, when turbid waters reach the mouth of the estuary and make this kind of interpretation possible. However, during the flood phase this technique is less useful for dynamic studies aiming at characterizing water exchange processes, because the water in the mouth of the estuary is then clearer (coastal water!) and, therefore, the role of turbidity as a natural tracer is less important.

2. On the other hand, the satellite-visible channels (both from Landsat TM and Spot HRV) do not penetrate much in the turbid water (Lathrop \& Lillesand 1989) reducing the utility of turbidity pattems in dynamic studies to surface waters. In shallow, well mixed and not stratified estuaries such as the TintoOdiel, this approach is very useful, but in stratified or deeper situations, the dynamic interpretation would be definitively more complex.

3. From the point of view of interpretation of the turbidity pattems, it is found that none of the analyzed images follow the flow scheme defined by CEDEX for an dominant eastward flow in the coastal waters. Apparently we need more images; thanks to the continuity of the AMA programme these may be available in the future. However, it is also possible that this is actually a less frequent situation than the CEDEX report suggests. There are two arguments to support this second hypothesis. The first one would be the existence of a constant westward littoral current in the general circulation pattern of the Golfo de Cádiz, which could only be counteracted and tumed eastward with very persistent winds in the opposite direction. The second one, as suggested by recent studies (Morales González 1993), is based on the time lag between the establishment of the tidal currents near the coast and in the estuaries of the region. Summarizing, it could be formulated as follows: as the tidal wave propagates along the Huelva coast from east to west, the coastal current moves westward during the flood phase, and during the ebb phase it moves eastward. The ebb tidal currents in the estuary mouth persist up to two hours after the theoretical tidal phase change (due to the inertia of the moving water, as was stated above). During this time lag the westward flood current has already established along the coast. This contributes both to the inflexion of the still ebbing current (helped by the Coriolis force) and to the westward displacement of the turbid waters that manage to turn around the jetty. 


\section{Conclusions}

The results of this study clearly demonstrate the usefulness of satellite images as a complementary source of information in the field of oceanographic techniques and in the characterization of the dynamic behaviour of coastal waters. Satellite images are particularly interesting in estuarine and coastal waters for two reasons: first of all because of their high dynamism and, secondly, because the collection of the basic data needed for this kind of studies normally requires extensive field work, which is both costly and time consuming.

In the Tinto-Odiel case, the results allowed us to achieve the following conclusions:

- Identification and synoptic mapping of the dynamic processes of interest during a theoretical tidal cycle (differential propagation of the tidal wave, location of the turbidity maximum, etc).

- An acceptable agreement between the turbidity patterns and the results obtained from the field campaigns in stable situations (hours two to five during the ebb or flood phase) allowed us to test the proposed flow schemes, contributing to a better qualitative and spatial characterization.

- Providing additional information of considerable environmental interest for mapping and characterizing synoptically the situations during the tidal phase change periods (the less stable and difficult to obtain by means of conventional techniques). This information is even more valuable because it is in these situations that the exchange between the estuarine and the coastal waters takes place.

- Finally, the image analysis supplied some basic information of interest for future environmental applications: pollutant diffusion in the estuary and coastal waters, contribution of the Punta Umbría Channel in the estuarine and coastal water exchange, assistance for the location of sampling points to evaluate the coastal waters quality. Its digital character also allows an easy integration in a GIS, as was demonstrated in the present study, the results of which will be integrated into the Environmental Information System of Andalusia (SinambA).

Acknowledgements. This study was supported by the Agencia de Medio Ambiente of the Junta de Andalucía, through the 'Specific Accordance' for collaboration between this organization and the Department of Physical Geography of the University of Sevilla. 


\section{References}

Anon. 1982. Estudio sobre la contaminación de la ría de Huelva. Comportamiento dinámico. Resultados de la campaña de campo. Report of the Centro de Estudios y Experimentación de Obras Públicas. Sevilla.

Anon. 1988. Clima Marítimo en la Ría de Huelva. Report of the Dirección General de Transportes, Consejería de Obras Públicas. Junta de Andalucía. Sevilla.

Balopoulos. E. T., Collins, M. B. \& James, A. E. 1986. Satellite images and their use in the numerical modelling of coastal processes. Int. J. Remote Sens. 7:905-919.

Borrego, J. \& Pendón, J. G. 1989. Caracterización del ciclo mareal en la desembocadura del río Piedras, pp. 97-100. XIII Congreso Español de Sedimentología, Bilbao.

Borrego, J. 1992. Sedimentología del estuario del río odiel (Huelva, SO España). Ph. D. Thesis, Universidad de Sevilla, Sevilla.

Chesire, H. M., Khorram, S. \& Brockhaus, J. A. 1985. Monitoring estuarine water quality from Landsat TM. Paper presented at the International Conference on Advanced Technologies for Monitoring and Processing Global Environmental Data. University of London.

Gil, J. 1987. Hidrología de la Ría de Huelva y su zona de influencia. Technical report no. 50, Instituto Español de Oceanografía, Madrid.

Lathrop, R. G. \& Lillesand, T. M. 1989. Monitoring water quality and river plume trnasport in Green Bay, Lake Michigan, with SPOT-1 imagery. Photogram. Eng. Remote Sens. 55: 349-354.

Morales González, J. A. 1993. Sedimentología del estuario del Guadiana (SW España-Portugal). Ph. D. Thesis. University of Sevilla, Sevilla.

Ojeda Zújar, J. 1992. Port et industries dans les estuaries: changements morphologiques et pollution. In: Le portage des eaux dans les Estuaries, pp. 25-30. Centre International de la Mer, Rochefort.

Received 9 February 1995;

Revision received 10 August 1995;

Accepted 20 September 1995.

\section{Cita bibliográfica:}

OJEDA, J.; SÁNCHEZ, E.; FERNÁNDEZ-PALACIOS, A.; Y MOREIRA, J.M. 1995. Study of the dynamics of estuarine and coastal waters using remote sensing: The tinto-Odiel estuary, SW Spain. In Journal of Coastal Conservation 1:109-118. Upsala. Sweden. 